\title{
28 Research Suare \\ Functional outcome of patients after shoulder hemiarthroplasty for neglected fractured proximal humerus
}

Aldo Fransiskus Marsetio

Universitas Indonesia

Iman Widya Aminata

Fatmawati General Hospital

Erick Wonggokusuma

Siloam Hospitals Kebon Jeruk

Ivan Mucharry Dalitan ( $\nabla$ dalitanivan@gmail.com )

Universitas Indonesia

Research article

Keywords: shoulder hemiarthroplasty, neglected proximal humerus fracture

Posted Date: January 8th, 2020

DOI: https://doi.org/10.21203/rs.2.20399/v1

License: (c) (i) This work is licensed under a Creative Commons Attribution 4.0 International License.

Read Full License 


\section{Abstract}

Introduction. The main objective of hemiarthroplasty is to restore the shoulder into the state of fully functional and pain-free. The most important steps in performing hemiarthroplasty are during obtaining proper head height and shaft length, retroversion correction, and tuberosities fixation. Literatures have shown significant improvement on patients performed shoulder hemiarthroplasty, either in the short and medium term or in the long term.

Methods. We did a retrospective cohort on patients with neglected proximal humerus fracture who underwent shoulder hemiarthroplasty at several hospitals in Jakarta, including Fatmawati general hospital, Siaga Raya hospital, Siloam hospital and Mitra Kemayoran hospital. Patients who underwent surgery within 2015 to 2018 were enrolled in this study. All patients with neglected Neer 3-part or Neer 4part proximal humerus fracture, confirmed by x-ray and computed tomography scans, were included. Patients were referred to the surgeon at least 2 weeks after injury

Result. Hemiarthroplasty result in satisfactory functional outcomes, with ASES score Preoperative (median (range)) 4.9 (5-37) improved to Postoperative (Mean \pm SD) $67.27 \pm 13.37$. Despite the Age at surgery (years, Mean \pm SD) $63.87 \pm 14.65$ are in the elderly group and timing of the operation relative to the initial trauma is (median, range) 13 weeks (2-156), hemiarthroplasty still result in a satisfactory functional outcome even though our patients fracture pattern were Neer 3 and Neer 4.

Conclusion. Hemiarthroplasty in neglected three- and four- part proximal humerus fracture is positively correlated with satisfactory clinical and functional outcomes even with associated AVN of humeral head despite the age and the timing of operation.

\section{Introduction}

The concept of shoulder hemiarthroplasty firstly pioneered by Themistocles Glück. ${ }^{1}$ He designed a schematic of shoulder hemiarthroplasty using ivory and cadaveric bones in 1891. This schematic was then used to perform the first metal shoulder replacement. Jules-Emile Péan conducted the procedure using metal implant in France, Paris in March 11, 1893, which is 25 years earlier than the first metal hip replacement. ${ }^{2} \mathrm{He}$ implanted a prosthesis consisted of platinum stem and rubber ball head with metal loops, into tuberculous arthritis shoulder of a 37-year-old male. Although it had to be removed 2 years after due to infection, but it changed the course of shoulder arthroplasty history.

The first anatomically-shaped modern metal hemiarthroprosthesis made of chromium cobalt alloy was pronounced by Krueger. ${ }^{3}$ It was implanted on patient with avascular necrosis of the humeral head, by preserving rotator cuff insertions to bone. It resulted a well-functioning and painless shoulder. The model was then refined further by Charles Neer. ${ }^{4}$ Made of inert and stronger material, longer stem, larger interface for osseointegration, and preservation of normal anatomy were the main feature of 
unconstrained Neer 1 prosthesis (Fig. 1). The prototype was then become the model development of nowadays hemiarthroplasty.

Hemiarthroplasty procedure only replace the humeral head, in which it will articulate with the native glenoid. There are two types of hemiarthroplasty available, either in the form of resurfacing (surface replacement) or stemmed prostheses (Fig. 2). Decision making on hemiarthroplasty surgery is mainly based on the vascularization status of the humeral head. ${ }^{5}$ Poor vascularization would result in avascular necrosis or collapse of the humeral head. Additionally, bone quality, complex fractures, and overall patient's health and social status are also taken into consideration. To be more specific, surface replacement is indicated in arthritic joint, avascular necrosis with still adequate supporting bone, and cartilage damage of humeral head. ${ }^{6}$ On the other hand, stemmed prosthesis are used to treat severe proximal humeral fracture (Neer 3- or 4-part), pathological fracture, and severe cartilage damage or avascular necrosis of humeral head. ${ }^{7}$

There are several factors determining the postoperative recovery phase after shoulder hemiarthroplasty surgery. It depends on the patient, surgical procedure, and type of prosthesis. Preoperative state, function of the muscles, quality of the bone and general functional status are factors from the patient. While surgical technique, intra-operative complications and requirement for rotator cuff repair are factors from the surgical procedure. Potential complications of shoulder replacement surgery may include hemorrhage, nerve damage, fracture, infection, dislocation, loosening, or anesthesia-related. ${ }^{8}$

The main objective of hemiarthroplasty is to restore the shoulder into the state of fully functional and pain-free. The most important steps in performing hemiarthroplasty are during obtaining proper head height and shaft length, retroversion correction, and tuberosities fixation. ${ }^{5}$ Literatures have shown significant improvement on patients performed shoulder hemiarthroplasty, either in the short and medium term, ${ }^{9,10}$ or in the long term. ${ }^{11}$ Although overall results show good pain relief, some also reports limited functional outcome. ${ }^{12-15}$

\section{Material And Methods}

Retrospective cohort study was done on patients with neglected proximal humerus fracture who underwent shoulder hemiarthroplasty at several hospitals in Jakarta, including Fatmawati general hospital, Siaga Raya hospital, Siloam hospital and Mitra Kemayoran hospital. Patients who underwent surgery within 2015 to 2018 were enrolled in this study. All patients with neglected Neer 3-part or Neer 4part proximal humerus fracture, confirmed by $x$-ray and computed tomography scans, were included. Patients were referred to the surgeon at least 2 weeks after injury. Patients with non-trauma cases (e.g. pathological fracture), any additional pathology (e.g. ankylosing spondylitis) and loss of follow up were excluded from the study.

\section{Preoperative Evaluation}


All patients' examination data especially regarding the shoulder range of motion, pain and daily functional status were documented from medical record. Pain and functional status were assessed using American Shoulder and Elbow Surgeons (ASES) standardized shoulder assessment score, Shoulder Pain and Disability Index (SPADI), and The Disabilities of the Arm, Shoulder and Hand (DASH) Score. These preoperative functional status data were also confirmed during follow up for more complete data. Additional data, such as age, gender, time interval between trauma and surgery were also recorded. Anteroposterior projection x-ray images of shoulder and three-dimensional computed tomography scan were also obtained for good preoperative planning.

\section{Operative Technique}

The patient is positioned in beach chair position. Deltopectoral approach is used to identify proximal portion of the humerus. Greater and lesser tuberosity were identified and retracted by stay sutures. Biceps tendon and pectoralis major tendon are identified and preserved. Head fragments are identified, removed and measured. Cancellous bone on the humeral head are removed and kept for graft.

Humerus medulla canal is reamed incrementally. Greater tuberosity and the attached rotator cuff muscle tendon units, lesser tuberosity and the attached subscapularis muscle tendon unit is released until it can be mobilized freely. Height of the stem were determined by using trial stem while maintaining traction on the arm at the appropriate humeral length. Head retroversion were determined at between $25-30^{\circ}$. Lateral fin is used as alignment marker with bicipital groove. The final stem was then inserted with cement.

Three pairs of holes are drilled on the proximal shaft in order to make secure sutures using heavy nonabsorbable sutures. Anterior medial suture is used to secure the lesser tuberosity and subscapular muscle tendon. Lateral suture is used to secure greater tuberosity and rotator cuff muscle tendons. Anterior suture is used to secure both tuberosities. Bone graft from the extracted humeral head were collected, and put on the anterior and posterior part of the humeral upper shaft and the prosthesis collar. Additional suture between tuberosities and through the anterior fin of the implant may be made.

\section{Post-operative Assessments and Rehabilitation}

Anteroposterior projection x-ray images of shoulder were obtained immediately after surgery. All patients underwent the same postoperative rehabilitation as the following: The patients are then instructed to put on a sling wear for the first 6 weeks. Early passive motion exercise and as-tolerated active motion are initiated. Active assisted range of motion is initiated at 3 weeks. Muscle strength exercise is initiated at 6 weeks. All patients were contacted for a follow up. Pain and functional status were re-assessed using ASES, SPADI and DASH scoring instruments.

\section{Results}

\section{Demographic Data}


Twenty-six patients had hemiarthroplasty surgery within 2015 to 2018 . However, only 15 were included in the study (Table 1). One patient was excluded due to non-trauma cases (pathological fracture), one patient was excluded due to additional pathology (ankylosing spondylitis) and nine patients were excluded due to loss of follow up. The shortest time to follow up was 7 months, while the longest time to follow up was 48 months. The shortest time of fracture negligence was 2 weeks, while the longest time was 156 weeks.

All surgeries have no major intraoperative complication; such as fractures or implant/instrument failure. No revision surgery was performed during follow-up period. All patients underwent the same physiotherapy regiment at twice a week for 2 months after the surgery. Pain on all patients were related to activity and limited range of movement.

Table 1

Demographic data of the patients

\begin{tabular}{|c|c|}
\hline \multicolumn{2}{|l|}{ Variables } \\
\hline $\begin{array}{l}\text { Total no. of patients (n, \%) } \\
\text { Male }(n, \%) \\
\text { Female }(n, \%)\end{array}$ & $\begin{array}{l}15(100 \%) \\
7(46.67 \%) \\
8(53.55 \%)\end{array}$ \\
\hline Age at surgery (years, Mean \pm SD) & $63.87 \pm 14.65$ \\
\hline Time until surgery (weeks, median, range) & $13(2-156)$ \\
\hline Length of follow up (months, Mean \pm SD) & $24.60 \pm 13.54$ \\
\hline $\begin{array}{l}\text { Neer classifications } \\
\text { Neer 3-part (n, \%) } \\
\text { Neer 4-part }(n, \%)\end{array}$ & $\begin{array}{l}3(20 \%) \\
12(80 \%)\end{array}$ \\
\hline Incidence of AVN (n, \%) & $5(33 \%)$ \\
\hline $\begin{array}{l}\text { ASES score } \\
\text { Preoperative (median (range)) } \\
\text { Postoperative (Mean } \pm \text { SD) }\end{array}$ & $\begin{array}{l}4.99(5-37) \\
67.27 \pm 13.37\end{array}$ \\
\hline $\begin{array}{l}\text { SPADI score } \\
\text { Preoperative (median (range)) } \\
\text { Postoperative (Mean } \pm \text { SD) }\end{array}$ & $\begin{array}{l}93.85(74-100) \\
35.03 \pm 14.41\end{array}$ \\
\hline
\end{tabular}

\section{Relationship with functional score}

Although hemiarthroplasty procedure result in a satisfactory functional outcome, statistic analysis found no significant difference of functional score (measured by ASES and SPADI) in regards of the geriatric age group $(p>0.05)$. No association were also found in regards of time of fracture negligence $(p>005)$. Due to small number of sample and wide variety of the data, our data has wide range of confidence interval. (Table 2 and Table 3) 
Table 2

Relationship between age of patient and functional score in independent T-test

\begin{tabular}{|lll|}
\hline Variables & Sig. (2-tailed) & $\mathbf{9 5 \%} \mathrm{Cl}$ \\
\hline Final post-operative ASES score & 0.829 & $-19.051-15.694$ \\
\hline ASES score difference pre- and post-surgery & 0.750 & $-14.985-11.056$ \\
\hline Final post-operative SPADI score & 0.964 & $-17.075-16.361$ \\
\hline SPADI score difference pre- and post-surgery & 0.867 & $-17.226-20.137$ \\
\hline \multirow{2}{*}{ significant at $\mathrm{p}<0.05 ; 95 \% \mathrm{Cl}, 95 \%$ confidence interval } & \\
\hline
\end{tabular}

Table 3

Relationship between time of fracture negligence and functional score in independent T-test

\begin{tabular}{|lll|}
\hline Variables & Sig. (2-tailed) & $\mathbf{9 5 \%}$ Cl \\
\hline Final post-operative ASES score & 0.345 & $-21.755-8.184$ \\
\hline ASES score difference pre- and post-surgery & 0.502 & $-8.733-16.947$ \\
\hline Final post-operative SPADI score & 0.632 & $-20.332-12.801$ \\
\hline SPADI score difference pre- and post-surgery & 0.105 & $-3.253-30.423$ \\
\hline *significant at $\mathrm{p}<0.05 ; 95 \% \mathrm{Cl}, 95 \%$ confidence interval & \\
\hline
\end{tabular}

\section{Discussion}

There are two main considerations for shoulder arthroplasty, including fracture patterns and patient characteristics. The fracture patterns indicated for arthroplasty are head-splitting patterns, fracture dislocations, and fractures classified as Neer three- or four-part fractures. ${ }^{16}$ Some authors also recommend hemiarthroplasty in proximal humerus fracture with more than 20 degrees of varus malalignment and cannot be reduced intraoperatively. ${ }^{17}$ Porotic bone, malunion, nonunion, implant failure, or osteonecrosis after internal fixation using plate are also some other indications related to the bone condition. From the perspective of the patient characteristic, lower demand patients, geriatric patients, osteoporotic bone and unable to attend a routine supervised physical therapy program are preferable criteria for patients who will undergo hemiarthroplasty procedure. ${ }^{17}$

A few studies have proven that hemiarthroplasty can give reasonable pain relief in the shoulder. ${ }^{18-20}$ Regarding to appropriate outcomes and significant results of our data analysis, we can suggest that hemiarthroplasty can result in satisfactory functional outcomes, with improvement of postoperative ASES scores. Based on the result of this study, hemiarthroplasty in neglected proximal humerus fracture 
is positively correlated with satisfactory clinical and functional outcomes even when the surgeon has to deal with malunion, non-union, severe osteoporosis, significant bone loss, articular incongruity, displacement of the tuberosities, rotator cuff tears, associated soft-tissue contractures or AVN of the proximal humerus.

Our study also revealed despite the patients' age at surgery are in the elderly group and timing of the surgery relative to the initial trauma, hemiarthroplasty still result in satisfactory functional outcome even though our patients fracture pattern were Neer 3-part and Neer 4-part. The age of the patient also did not influence the final outcome in other similar studies. Bosch et al stated that what seems to be more important for rehabilitation is the cooperation and mental status of patients, rather than their age. If the patient is closed monitored and instructed by his surgeon the results are more predictable, because the physiotherapy can be focused to the most impaired function. ${ }^{21}$

A meta-analysis by Bhandari et $\mathrm{al}^{22}$ was unable to determine the optimal intervention in patients with displaced four part fractures of the proximal humerus whether non operative, open reduction internal fixation or arthroplasty. Treatment with open reduction and internal fixation also gave good result despite the age of patient. ${ }^{23}$ But on the study there was a patient requiring a revision with hemiarthroplasty due to loss of fixation and osteoporotic collapse was thought to be one of the suspected cause. This is also one of the reason that hemiarthroplasty is the choice of intervention in a neglected Neer 3 and Neer 4 fracture. Hemiarthroplasty is used in non-re-constructible fracture and poor bones quality. ${ }^{17}$ A study of delayed open reduction and internal fixation in proximal humerus fracture further strengthen our choice of treatment with the high rate of humeral head necrosis in the Neer 3-part and Neer 4-part group. ${ }^{24}$ Late shoulder hemiarthroplasty is technically difficult and the results are inferior to those reported for acute humeral head replacement, nonetheless remains a satisfactory reconstructive option when primary treatment fails. It was previously stated that the patients who had been managed non operatively had a better result when undergoing hemiatrhoplasty than those who have been operated with plate and screw. $^{21}$

Besides surgical technique and prosthetic design, there are several factors determine the good functional outcome on patients who had hemiarthroplasty such as proper position of the tuberosity, humeral height, humeral head version, Stem design and material. 5,25 Tuberosity healing is critical for a successful outcome after hemiarthroplasty. ${ }^{16}$

\section{Conclusion}

Hemiarthroplasty in neglected three- and four- part proximal humerus fracture is positively correlated with satisfactory clinical and functional outcomes even with associated AVN of humeral head despite the age and the timing of operation.

\section{Declarations}


Ethics approval and consent to participate

Ethics approval is not necessary for this study.

Consent for publication

Written consents have been received from all patients included in this paper to be included in this paper and for their data to be published.

Availability of data and materials

The datasets during and/or analysed during the current study available from the corresponding author on reasonable request.

Competing interests

The authors declare that they have no competing interests.

\section{Funding}

This study received no funding from external sources.

Authors' contributions

AFM made the concepts of this study, performed examinations, and analysed the data; IWA performed the operations and analysed the data; EW did the interview, examination, and data analysis; IMD did the data analysis and wrote the manuscript. All authors read and approved the final manuscript.

Acknowledgements

$\mathrm{n} / \mathrm{a}$

\section{Abbreviations}

ASES : American Shoulder and Elbow Surgeons Standardized Shoulder Assessment

AVN : avascular necrosis

DASH : The Disabilities of the Arm, Shoulder and Hand

SPADI : Shoulder Pain and Disability Index

\section{References}

1. Gelenkersatz J, Wessinghage D. Beitrag zur Geschichte Themistocles Gluck. 1991;129. 
2. JE P. Des moyens prosthétiques destines a obtenir la répa- ration de parties osseuses. Gaz Hop Paris. 1894;67:291-302.

3. Krueger FJ. A vitallium replica arthroplasty on the shoulder; a case report of aseptic necrosis of the proximal end of the humerus. Surgery. 1951;30(6):1005-1011.

4. Neer CS, Brown TH, McLaughlin HL. Fracture of the neck of the humerus with dislocation of the head fragment. Am J Surg. 1953;85(3):252-258. doi:10.1016/0002-9610(53)90606-0

5. Jones RB. Hemiarthroplasty for Proximal Humeral Fractures Indications, Pitfalls, and Technique. Bull Hosp Joint Dis. 2013;71(2):S60-3.

6. Jensen K. Humeral resurfacing arthroplasty: Rationale, indications, technique, and results. Am J Orthop (Belle Mead NJ). 2008;36:4-8.

7. Brown FM. Nursing care after a shoulder arthroplasty. Orthop Nurs. 2008;27(1):3-11. doi:10.1097/01.NOR.0000310604.70247.e9

8. Wand RJ, Bigsby E, Wand JS, Dear KEA. A review of Shoulder replacement surgery. Acorn. 2013;26(4):38-43. doi:10.1177/175045891602201102

9. Edwards TB, Kadakia NR, Boulahia A, et al. A comparison of hemiarthroplasty and total shoulder arthroplasty in the treatment of primary glenohumeral osteoarthritis: Results of a multicenter study. $J$ Shoulder Elb Surg. 2003;12(3):207-213. doi:10.1016/S1058-2746(02)86804-5

10. Radnay CS, Setter KJ, Chambers L, Levine WN, Bigliani LU, Ahmad CS. Total shoulder replacement compared with humeral head replacement for the treatment of primary glenohumeral osteoarthritis: A systematic review. J Shoulder Elb Surg. 2007;16(4):396-402. doi:10.1016/j.jse.2006.10.017

11. Haines IA, Trail IA, Nuttall D, Birch A, Barrow A. The results of arthroplasty in osteoarthritis of the shoulder. J Bone Jt Surg - Ser B. 2006;88(4):496-501. doi:10.1302/0301-620X.88B4.16604

12. Boileau P, Krishnan SG, Tinsi L, Walch G, Coste JS, Molé D. Tuberosity malposition and migration: Reasons for poor outcomes after hemiarthroplasty for displaced fractures of the proximal humerus. J Shoulder Elb Surg. 2002;11(5):401-412. doi:10.1067/mse.2002.124527

13. Noyes MP, Kleinhenz B, Markert RJ, Crosby LA. Functional and radiographic long-term outcomes of hemiarthroplasty for proximal humeral fractures. J Shoulder Elb Surg. 2011;20(3):372-377. doi:10.1016/j.jse.2010.06.009

14. Plausinis D, Kwon YW, Zuckerman JD. Complications of humeral head replacement for proximal humeral fractures. Instr Course Lect. 2005;54:371-380.

15. Antuña SA, Sperling JW, Cofield RH. Shoulder hemiarthroplasty for acute fractures of the proximal humerus: A minimum five-year follow-up. J Shoulder Elb Surg. 2008;17(2):202-209. doi:10.1016/j.jse.2007.06.025

16. Chambers L, Dines JS, Lorich DG DD. Hemiarthroplasty for Proximal Humerus Fractures. Tech Shoulder Elb Surg. 2016;17(3):110-115. doi:10.1097/BTE.0000000000000101

17. Ahmad CS, Cadet ER. Hemiarthroplasty for Three- and Four-part Proximal Humerus Fractures. J Am Acad Orthop Surg. 2012;20(1):17-27. 
18. Goldman RT, Koval KJ, Cuomo F, Gallagher MA, Zuckerman JD. Functional outcome after humeral head replacement for acute three- and four-part proximal humeral fractures. J Shoulder Elb Surg. 1995;4(2):81-86. doi:10.1016/S1058-2746(05)80059-X

19. Boons HW, Goosen JH, Van Grinsven S, Van Susante JL, Van Loon CJ. Hemiarthroplasty for humeral four-part fractures for patients 65 years and older a randomized controlled trial. Clin Orthop Relat Res. 2012;470(12):3483-3491. doi:10.1007/s11999-012-2531-0

20. Olerud P, Ahrengart L, Ponzer S, Saving J, Tidermark J. Hemiarthroplasty versus nonoperative treatment of displaced 4-part proximal humeral fractures in elderly patients: A randomized controlled trial. J Shoulder Elb Surg. 2011;20(7):1025-1033. doi:10.1016/j.jse.2011.04.016

21. Panagopoulos A, Tsoumpos P, Evangelou K, Georgiou C, Triantafillopoulos I. Late Prosthetic Shoulder Hemiarthroplasty after Failed Management of Complex Proximal Humeral Fractures. Adv Orthop. 2013;2013:1-9. doi:10.1155/2013/403580

22. Handoll HHG, Gibson JNA, Madhok R, Bhandari M, Matthys G, McKee MD. Four part fractures of the proximal humerus (multiple letters). J Orthop Trauma. 2004;18(6):390. doi:10.1097/00005131200407000-00012

23. Grawe B, Le T, Lee T, Wyrick J. Open Reduction and Internal Fixation (ORIF) of Complex 3- and 4-Part Fractures of the Proximal Humerus: Does Age Really Matter. Geriatr Orthop Surg Rehabil. 2012;3(1):27-32. doi:10.1177/2151458511430662

24. Lu Y, Jiang C, Zhu Y, Wang M, Bowles RJ, Mauffrey C. Delayed ORIF of proximal humerus fractures at a minimum of 3 weeks from injury: A functional outcome study. Eur J Orthop Surg Traumatol. 2014;24(5):715-721. doi:10.1007/s00590-013-1255-5

25. Kancherla VK, Singh A, Anakwenze OA. Management of Acute Proximal Humeral Fractures. J Am Acad Orthop Surg. 2017;25(1):42-52. doi:10.5435/jaaos-d-15-00240

\section{Figures}




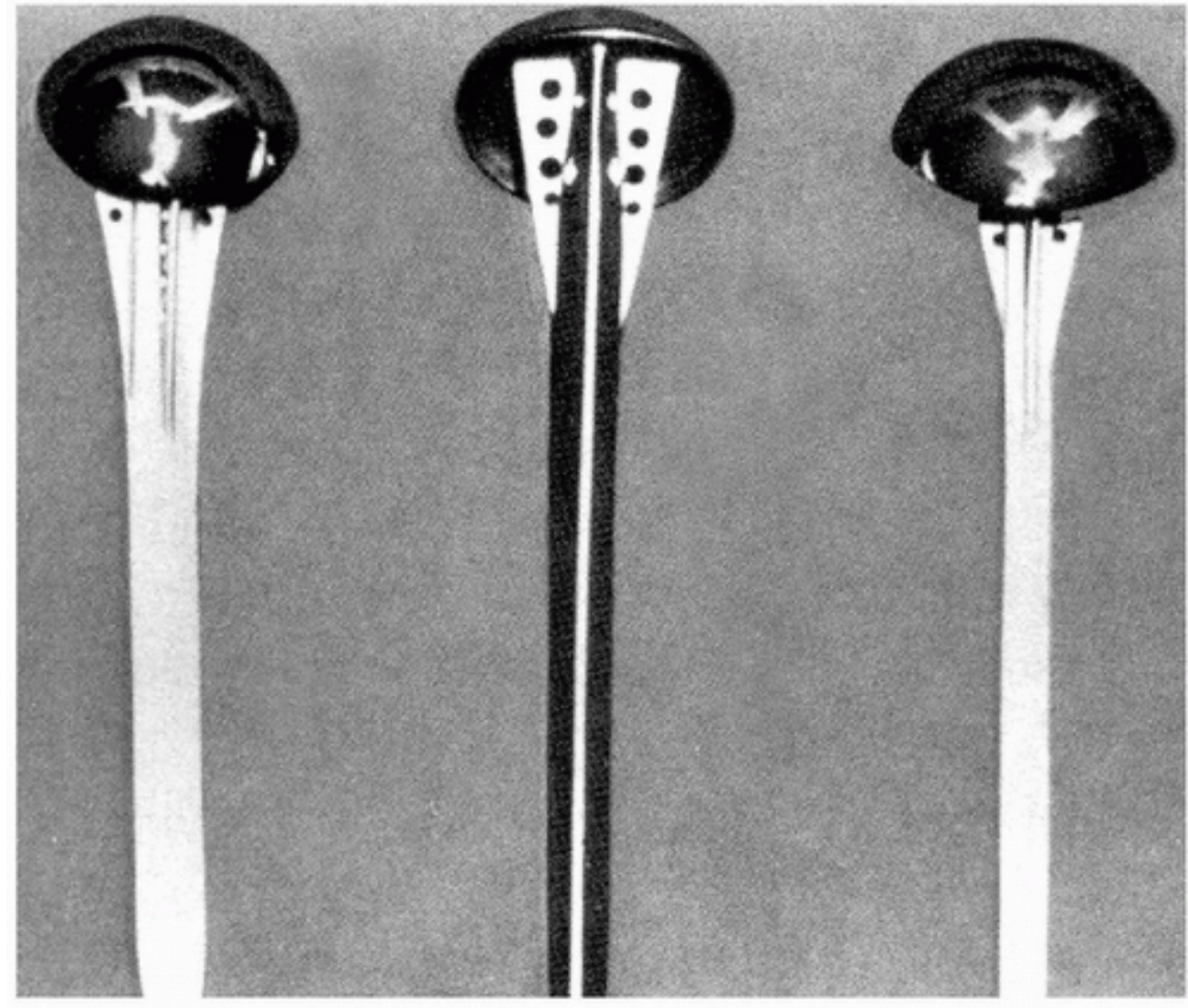

\section{Figure 1}

Model of Neer 1 prosthesis. (Taken from: Neer CS, Brown TH, Jr., McLaughlin HL. Fracture of the neck of the humerus with dislocation of the head fragment. Am J Surg 1953;85:252-258.)
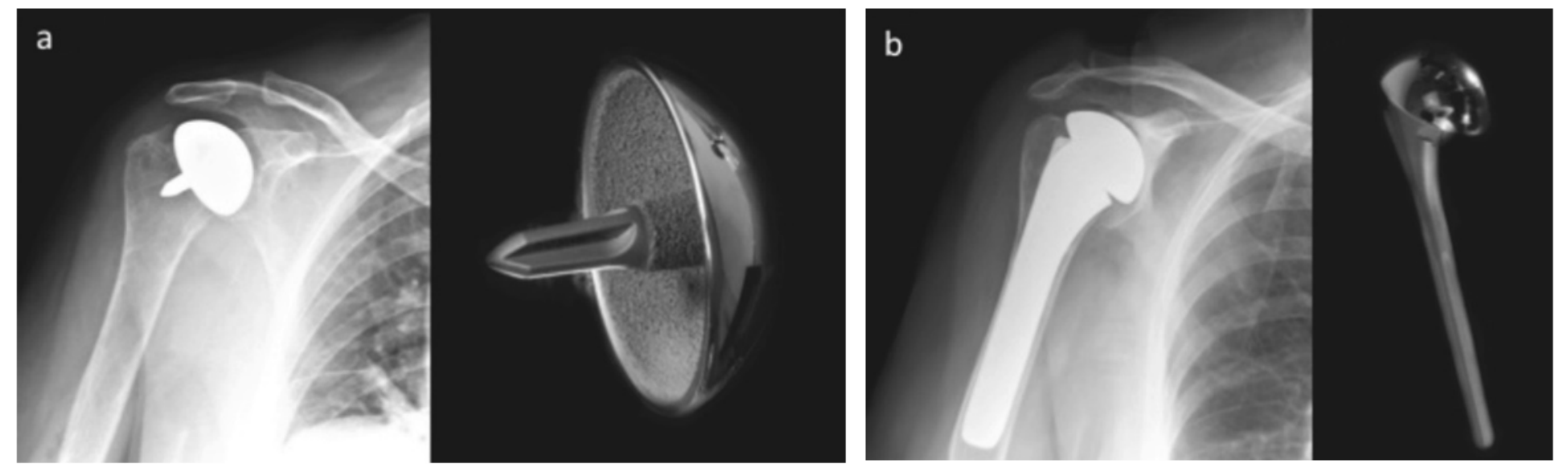

\section{Figure 2}

Two types of hemiartrhroplasty: surface replacement (a), and stemmed prostheses (b). (Taken from: Wand RJ, Dear KE, Bigsby E, Wand JS. A review of shoulder replacement surgery. J Perioper Pract. 2012 Nov;22(11):354-9.) 